\title{
Review Article \\ The Role of Reactive Oxygen Species in Myelofibrosis and Related Neoplasms
}

\author{
Mads Emil Bjørn ${ }^{1,2}$ and Hans Carl Hasselbalch ${ }^{1}$ \\ ${ }^{1}$ Department of Hematology, Roskilde Hospital, Køgevej 7-13, 4000 Roskilde, Denmark \\ ${ }^{2}$ Institute for Inflammation Research, Department of Rheumatology, Rigshospitalet, Blegdamsvej 9, 2100 Copenhagen, Denmark \\ Correspondence should be addressed to Mads Emil Bjørn; meb@c.dk
}

Received 2 July 2015; Accepted 9 August 2015

Academic Editor: Pham My-Chan Dang

Copyright (c) 2015 M. E. Bjørn and H. C. Hasselbalch. This is an open access article distributed under the Creative Commons Attribution License, which permits unrestricted use, distribution, and reproduction in any medium, provided the original work is properly cited.

\begin{abstract}
Reactive oxygen species (ROS) have been implicated in a wide variety of disorders ranging between traumatic, infectious, inflammatory, and malignant diseases. ROS are involved in inflammation-induced oxidative damage to cellular components including regulatory proteins and DNA. Furthermore, ROS have a major role in carcinogenesis and disease progression in the myeloproliferative neoplasms (MPNs), where the malignant clone itself produces excess of ROS thereby creating a vicious self-perpetuating circle in which ROS activate proinflammatory pathways (NF- $\kappa$ B) which in turn create more ROS. Targeting ROS may be a therapeutic option, which could possibly prevent genomic instability and ultimately myelofibrotic and leukemic transformation. In regard to the potent efficacy of the ROS-scavenger N-acetyl-cysteine (NAC) in decreasing ROS levels, it is intriguing to consider if NAC treatment might benefit patients with MPN. The encouraging results from studies in cystic fibrosis, systemic lupus erythematosus, and chronic obstructive pulmonary disease warrant such studies. In addition, the antioxidative potential of the widely used agents, interferon-alpha2, statins, and JAK inhibitors, should be investigated as well. A combinatorial approach using old agents with anticancer properties together with novel JAK1/2 inhibitors may open a new era for patients with MPNs, the outlook not only being "minimal residual disease" and potential cure but also a marked improvement in inflammationmediated comorbidities.
\end{abstract}

\section{Introduction}

The Philadelphia negative chronic myeloproliferative neoplasms (MPNs) encompass essential thrombocythemia (ET), polycythemia vera (PV), and myelofibrosis (MF). These neoplasms arise due to an acquired stem cell lesion with subsequent clonal evolution being driven by several mutations, including the highly prevalent JAK2V617F somatic mutation in PV (in $>95 \%$, and in about $50 \%$ of patients with ET and PMF, resp.) and the CALR and MPL somatic mutations [19]. These mutations are virtually mutually exclusive and are all considered "second hits" or "driving mutations" within the MPNs whereas the primary genetic hit or "founding mutation" remains unknown [4].

Common clinical denominators for the MPNs are high rates of thrombohemorrhagic complications, hypermetabolic symptoms, splenomegaly, uncontrolled myeloproliferation, low-grade chronic inflammation, a massive inflammationmediated comorbidity burden, and immune-deregulation [10-16]. The MPNs have an inherent propensity to progress in a biological continuum from early cancer stages (ET/PV) to more advanced cancer stages (MF or acute myeloid leukemia (AML)) $[17,18]$. The concept of such a biological continuum is being increasingly recognized and supported by clinical and molecular studies, the latter displaying increasing JAK2V617F allelic burden throughout the stages. The fact that a JAK2 positive phenotype only persists in $20-50 \%$ of the cases when MPNs transform to AML (or even develops biphenotypic AML) also demonstrates the inherent risk of subclone formation which is a characteristic shared by many other cancers [19-23]. Consequently, the malignant clones are heterogeneous and thus difficult to target with chemotherapy, accounting for the inferior survival in MPN associated AML compared to de novo AML [24-26]. 
The MPNs have recently been described as "A Human Inflammation Model," in which the fuel that feeds the fire is low-grade chronic inflammation [27]. The hypothesis is that the MPN-with uncontrolled myeloproliferation and uncontrolled cytokine secretion as a consequence of constitutively activated JAK-STAT signalling-by itself creates a proinflammatory milieu in the bone marrow and in the circulation. This proinflammatory milieu founds increasing genomic instability accounting for the propensity of the MPNs to acquire new mutations facilitating clonal evolution and ultimately progression to myelofibrosis and AML. It also links the MPNs with a heavy inflammation-mediated comorbidity burden, including premature atherosclerosis, other inflammatory diseases, and second cancers [22, 27-38]. In this context, it has been known for several years that chronic inflammation per se increases the risk of cancer development, solid as well as hematological, but the major questions in MPNs are, among others, how low-grade inflammation is eliciting genomic instability and clonal evolution and how the founding clone evades the immune system.

In MPNs, the optimal therapeutic goals are to normalize peripheral blood counts, minimize symptoms, prevent vascular complications, restore bone marrow architecture/morphology, and eliminate the risk of progression to $\mathrm{MF}$ or evolution to AML. It is crucial to acknowledge that the majority of ET and PV patients have long lifeexpectancies and therefore treatment related toxicities and long-term side effects influence treatment options [39-42]. The therapeutic agents display striking differences. Treatment with interferon-alpha2 (IFN) has been used successfully for decades, demonstrating its ability to normalize blood counts in the majority of patients, to reduce the JAK2V617F (and CALR) allelic burden, and to restore bone marrow morphology and induce major molecular remission in a subset of patients [43-55]. Because of the immune-enhancing properties, some patients experience autoimmune phenomena, primarily thyroiditis, during IFN treatment. A subset of patients also experiences symptoms similar to those arising in patients with systemic inflammation, including chronic fatigue, flue-like symptoms with low-grade fever, weight loss, and depression all symptoms being associated with chronic inflammation [56-58]. Despite undisputed hematological efficacy and safety being shown in a large number of single-arm IFN studies, similar results obtained from large randomized studies between IFN and the most widely used cytoreductive agent in MPNs, hydroxyurea, are still lacking. Most MPN experts agree that HU increases the risk of skin cancer and concern is increasing in regard to its potential of inducing AML after long-term use (>10 years) [59-64]. With the introduction of JAK inhibitors, the therapeutic landscape has expanded considerably. However, these novel agents potently suppress virtually all immune cells including NK-cells, CD4+ T-cells (Th1 and Th17), regulatory T-cells, macrophages, and dendritic cells (DCs) with ensuing impairment of immune regulation and consequently an increased risk of infections [65-71]. This risk is well documented and involves mainly urinary tract infections and herpes zoster but also more rare infections such as tuberculosis, toxoplasmosis, and progressive multifocal leukoencephalopathy [72-76].
Although patients are exposed to an increased risk of infections during treatment with JAK1/2 inhibitors, this novel treatment modality has definitely demonstrated its efficacy in terms of improvement of quality of life due to a rapid resolution of constitutional symptoms within days in concert with a marked reduction in symptomatic splenomegaly within the next weeks or months in the large majority of patients with myelofibrosis [77-80]. To this end, JAK1/2 inhibition in myelofibrosis is associated with an improved overall survival as well $[81,82]$. The impact of JAK1/2 inhibition on symptom burden and splenomegaly in myelofibrosis is considered to be driven mainly by its pronounced anti-inflammatory efficacy as evidenced by a marked reduction in several proinflammatory cytokines during JAK-inhibition therapy $[77,83]$. In this regard, the improved survival in ruxolitinibtreated MF patients is likely mainly explained by an improvement in inflammation-mediated comorbidities as well [84]. However, ruxolitinib has failed to demonstrate significant impact on the JAK2 clone [85] which substantiates the need for combinatorial approaches when treating MPNs [28].

Taking into account that chronic inflammation with the production of reactive oxygen species (ROS) may have an important role for the development and progression of MPNs-likely being a very potent driver of clonal evolution and mutagenesis in a vicious self-perpetuating circle-we herein will discuss the role of ROS in MPN pathogenesis and its impact upon comorbidity burden, immune regulation, and disease progression [27, 29, 86-90].

\section{Reactive Oxygen Species}

Reactive oxygen species (ROS) are a group of oxygencontaining molecules involved in many biological processes including normal cellular signalling and immune defence. Consequently, lacking the ability to produce ROS results in organ dysfunction and disease as evidenced by, for example, chronic granulomatous disease in which the immune system is unable to combat invading bacteria and fungi due to impaired production of ROS by neutrophils [9195]. However, the same ROS compounds are also involved in several inflammation-driven diseases where an excess of ROS production is thought to account for the tissue damage, dysfunction, and fibrosis associated with the diseases [96, 97]. In addition, elevated levels of ROS, often referred to as oxidative stress, have a major role in cancer development, both in solid tumors and in hematological malignancies $[86-90,97]$. There is no clear cut-off that defines exactly which compounds are to be included in the ROS category, and often nonoxygen molecules buffering ROS levels are also included in the analysis of cellular oxidative status. The molecules superoxide $\left(\mathrm{O}_{2}{ }^{-}\right)$and hydrogen-peroxide $\left(\mathrm{H}_{2} \mathrm{O}_{2}\right)$ are obvious ROS, but intracellular levels of glutathione and reduced glutathione are also crucial in the cellular redox interplay. Hydrogen-peroxide is of particular interest since it can freely diffuse across cellular membranes and interact with cells in close proximity to the $\mathrm{H}_{2} \mathrm{O}_{2}$ producing cells. This includes the endothelial cells within the intima of artery walls, and oxidative stress has already been linked to cardiovascular 
diseases, especially the development of premature atherosclerosis in chronic inflammatory diseases [96, 98-100]. $\mathrm{H}_{2} \mathrm{O}_{2}$ has been shown to activate NF- $\kappa \mathrm{B}$ pathway, thus creating selfperpetuating vicious circles in which inflammation creates ROS which in turn creates more inflammation [101-103]. To avoid such situations, the system has a fail-safe: suppressors of cytokine signalling (SOCS), a family of proteins dedicated to creating negative feedback loops. They are normally activated by inflammatory mediators such as IFN, IL-4, TNF-alpha, and $\mathrm{H}_{2} \mathrm{O}_{2}[104,105]$. Activated SOCS proteins bind to JAKs disrupting the JAK-STAT pathway, thereby ensuring that the inflammatory process is not being sustained. However, in MPNs, this pathway is constitutively activated and the much warranted SOCS brake is overruled. Furthermore, aberrant methylation of SOCS-coding DNA and consequent dysregulation of SOCS have also been reported in MPNs $[106,107]$.

\section{Hepatitis $C$ as a Model of Inflammation- Mediated Fibrosis and Cancer Development: Similarities to MPNs as "A Human Inflammation Model for Cancer Development"}

The initiating event in hepatitis $\mathrm{C}$ is a viral infection. This results in chronic inflammation, increased production of ROS and consequently oxidative stress, inability of the immune system to clear the infected cells, an increased risk of progression to terminal cirrhosis, and ultimately an increased risk of developing hepatocellular carcinoma (HCC) or lymphoma [108-113]. In MPNs, the initiating event is unknown, but after acquisition of the JAK2 mutation, MPNs (much like hepatitis patients) exhibit evidence of low-grade chronic inflammation with ensuing fibrosis and bone marrow failure in addition to an increased risk of developing AML. Another similarity is the inability of the host immune system to identify and clear the fundamental problem, for example, the malignant clone in regard to MPNs. Another striking similarity is the existence of a common effective treatment modality: the very potent immune-enhancing, antiviral agent IFN which has been used successfully for decades in hepatitis patients as well as in MPN patients. In this regard, it has recently been hypothesized that a virus infection (e.g., human retrovirus) might be implicated in MPN pathogenesis [27, 114]. It is also of particular interest to note that oxidative stress has been implicated in the therapeutic response. Thus, it was demonstrated, that increasing levels of ROS disrupt IFN signalling, thus counteracting therapy [115].

\section{ROS and MPNs}

The ROS molecules are produced mainly by neutrophils, macrophages, and monocytes. In the context of MPNs, this is crucial, since the MPN cells are clonal and autonomously dysregulated and have been shown to produce excessive ROS in vitro [87]. Furthermore, MPN patients demonstrate elevated levels of ROS in vivo $[86,116]$. An increased ROS production has been observed in other cancers, and in some cases the cancer cells express catalase (the enzyme that metabolizes $\mathrm{H}_{2} \mathrm{O}_{2}$ ) in excess and in addition produce large amounts of $\mathrm{H}_{2} \mathrm{O}_{2}$. In this way, the malignant clone itself avoids the toxic effects of $\mathrm{H}_{2} \mathrm{O}_{2}$ and suppresses the neighbouring healthy cells (ROS induce apoptosis in healthy cells) thereby facilitating clonal expansion [117-126]. This mechanism has not yet been established in MPNs but certainly warrants further investigation, especially since the excessive ROS production in MPNs gives rise to a proliferative advantage to JAK2 positive clones [28, 87, 127, 128] (Figure 1). In this regard, the model proposed by Marty et al. is in agreement with the MPN inflammation model and excessive ROS accumulation in a vicious self-perpetuating circle. In this context, considering the role of NF-E2 in MPN disease pathogenesis, it is intriguing to speculate if NF-E2 may contribute in driving the vicious inflammation wheel, including ROS accumulation as most recently discussed $[29,129-134]$. On the other hand, it has also been demonstrated that the hematopoietic stem cell niche (HSC) in MPNs downregulates catalase activity resulting in an increase in oxidative DNA damage (8-oxo-G) and subsequent double-stranded- (ds-) DNA breaks, a widely accepted measure of ROS induced DNA damage, and perhaps in this way induces instability of the HSC niche [87].

In a mouse model, ds-DNA breaks were shown to be a consequence of ROS accumulation, and it was also shown that the CD34+ HSCs themselves produced this excess ROS, probably as a consequence of catalase downregulation [87, 127]. Furthermore, a functional lack of superoxide dismutase (SOD) activity could also be of importance. ROS negatively influence the AKT pathway, which in turn influences Forkhead $\mathrm{O} /$ FoxO which regulates the transcription of several antioxidative defence pathways, including GPx, catalase, and SOD [135]. These mice developed aggressive PV phenotype but when they were treated with the potent ROS-scavenger molecule n-acetyl-cysteine (NAC) they developed normal phenotype, demonstrating the direct role in MPN disease development and disease progression [87]. This was substantiated by the finding that NAC treatment of the PV phenotype mice delayed progression to MF phenotype when compared to nontreated mice.

The damaging effects of ROS (besides the proliferative advantage) are also attributed to the consequent oxidation of lipids, proteins, and, most importantly, the ds-DNA breaks due to oxidation. In healthy cells, this insult will be rapidly repaired but a hallmark of most cancers is a defective DNA repair (sometimes even induced by therapy, e.g., hydroxyurea). Furthermore, the response to DNA damage is also affected as demonstrated by the negatively regulated p53 pathway in MPNs [136]. This is also demonstrated in MPNs, where the CHEK2 germline mutations, which are associated with ET and PV, account for an increased risk of developing an MPN. Together with other proteins, the CHEK2 proteins are associated with DNA damage and binding of TP53 (p53) and CHEK2 are involved in many cancers [137-143]. Consequently, harbouring this CHEK2 mutation can result in inadequate DNA repair and consequently increased risk of developing (and sustaining) genetic hits in several cancer types. It is intriguing to consider if germline CHEK2 mutation accounts for the initial genetic 


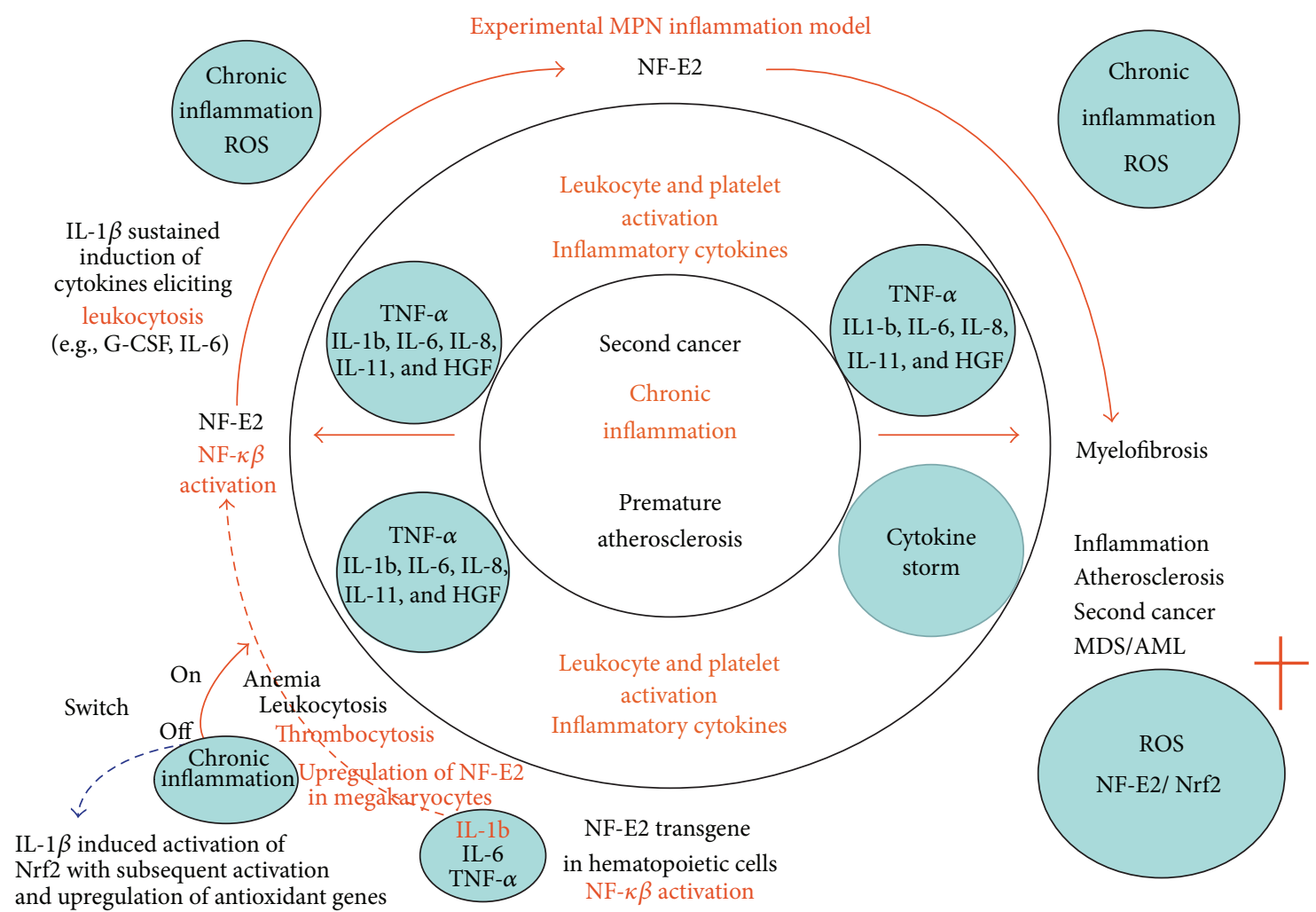

FIGURE 1: Sustained NF-E2 expression likely elicits a pronounced oxidative stress milieu with excessive ROS giving rise to myeloid expansion with leukocytosis and excessive thrombocytosis and inflammation-mediated in vivo activation of leukocytes and platelets, thereby further promoting a sustained, self-perpetuating release of inflammatory products. In this vicious circle, an oxidative stress burden with NF-E2 domination over Nrf2 promotes ROS accumulation and megakaryocytic differentiation. Increasing oxidative stress-induced DNA damage of hematopoietic stem cells (HSCs) elicits genomic instability and clonal MPN evolution with accumulation of mutations ultimately terminating in myelofibrotic and leukemic transformation. A relative deficiency of Nrf2 may also result in expansion of the HSC and progenitor cell compartment and ultimately migration of HSCs from their stem cell niches into the circulation ("leaving the burning nest") to seed in the spleen and liver (myelofibrosis with myeloid metaplasia). The vicious circle may be locked by early intervention with interferon-alpha2 (stopping the fuel to the fire) in combination with a JAK1-2 inhibitor (e.g., ruxolitinib) and a statin, the latter agents "cooling down the system" by their highly potent anti-inflammatory properties which may actually be enhanced (synergism) when being administered simultaneously. With permission from Leukemia Research [29].

instability in some MPN patients. In time and by "chance" this might result in a somatic JAK2 mutation with ensuing increased production of ROS, clonal expansion, and increasing genomic instability due to ineffective DNA repair and an increase in ROS induced DNA damage, all of which further facilitate disease progression with subclone formation and inflammation-mediated bone marrow fibrosis. The role of chronic inflammation and ROS in MPN pathogenesis has most recently been substantiated in a mouse model, in which mice were exposed to the highly potent inflammatory compound, formaldehyde (FA), by inhalation [144]. This agent induced bone marrow toxicity with typical MPNlike alterations in the mice, including an increased number of megakaryocytes and myelofibrosis in concert with the development of anemia, leukopenia, and thrombocythemia. Highly interestingly, these changes were accompanied by evidence of oxidative stress and inflammation in the bone marrow as assessed by significant increases in ROS levels, increased NF- $\kappa \mathrm{B}$ activity at both mRNA and protein levels, and significant increases in the inflammatory markers, TNFalpha and IL-1beta, as well [144]. These observations are in accordance with studies demonstrating that oxidative stress in hematopoietic stem cells can lead to DNA damage, premature senescence, and loss of stem cell function [145]. Accordingly, all together these findings are supportive of the concept that chronic inflammation by induction of oxidative stress and an inflammatory bone marrow microenvironment may give rise to DNA damage and likely an impaired stem cell function with ensuing development of myelofibrosis.

In hepatitis, it has been demonstrated, that the excess of ROS and consequent oxidative stress inhibits IFN signalling, thus counteracting the normal immunosurveillance by NKcells and CD8+ cytotoxic T-cells (CTLs) [115]. The reduced IFN signalling and ensuing reduction of MHC-I expression by virally infected cells provide an escape route from the innate and adaptive immunosurveillance. A prerequisite of this model is that the MHC-I expression is low enough to avoid CTL activation by antigen recognition, but also 
high enough to avoid "missing self" activation of NK-cells. This model deserves to be tested in MPNs to elucidate if increased ROS levels might facilitate both clonal expansion and immune evasion, implying ROS-mediated inhibition of IFN signalling and the immune evasion to exhibit dual actions. In this regard, reduced MHC-I expression might keep the tumor below detection limit of CTLs, and even if a tumor cell is indeed detected, probably due to threshold expression of "self" by MHC-I, the consequent IFN signalling from the activated NK-cell will likely have only a limited impact since the pathway is functionally blocked by excess of ROS. By this mechanism, recruitment and activation of other immune cells, in particular macrophages, may be inhibited and the immune response remains unamplified and thus ineffective in combating the clone. This concept is partly supported by the finding of downregulation of HLA expression in ET, PV, and MF and further supported by efficacious treatment with IFN, which increases MHC-I expression of the clonal cells (thus making them "legitimate" targets for CTLs) but also increases the NK-cell compartment, thus inducing the much warranted amplification of the immune system. IFN also mobilizes dormant stem cells rendering them susceptible to targeted therapies [146-149].

Since ROS appear to play a crucial role in disease progression of MPNs, the targeting of ROS seems intuitive, especially since the increased ROS can interfere with both endogenous tumor surveillance and treatment response. Treatment with NAC has been used successfully in an in vivo mouse model after JAK2V617F bone marrow transplant, but never in human MPN subjects. The majority of experiences with human NAC treatment are based on the treatment of patients suffering from paracetamol poisoning. In this setting, the NAC treatment is intensive and of short duration. NAC treatment has also been investigated in spinal cord injuries but again the treatment duration is short [150-153]. However, longer exposure has been investigated in chronic pulmonary diseases: chronic obstructive pulmonary disease (COPD) and cystic fibrosis (CF). Both diseases have a significant inflammatory component, and both diseases showed positive responses to NAC treatment with fewer exacerbations (COPD) and more stable lung function (CF) in the NACtreated groups [154-156]. Similar results were obtained in patients suffering from systemic lupus erythematosus (SLE) [157].

In order to target MPN related oxidative stress, it is important to acknowledge that the optimal level of ROS is not known. In the experimental MPN models, treatment with NAC almost totally removed any existing ROS, which in an experimental model might give satisfying results but in a human trial might result in a dismal outcome [87, 127]. In vivo, ROS are needed to some extent to ensure normal cellular signalling and to enable the immune system in combating invading bacteria and an obvious problem might be an increase in infectious diseases and (other) neoplastic diseases. However, this has not been identified so far with NAC treatment of COPD and CF, both diseases otherwise heavily burdened by (chronic) infections and the NAC treatment resulted in disease relevant improvements.

\section{Discussion and Perspectives}

The MPNs are clonal neoplasms intimately associated with a dysregulated immune system [16, 17, 148, 149, 158-160]. As in many other diseases, inflammation and excess generation of ROS are thought to play a major role, both in disease initiation and associated inflammation-mediated comorbidities $[27,28,84,135]$. The initiation of disease is probably a consequence of defective DNA repair and/or increased acquisition of DNA damage. This could be caused by many factors, for example, germline CHEK2 mutation $[142,143]$. Of note, it is also intriguing to consider that the initiation of the disease might be consequent to a "fertile ground" changing the fitness of the stem cell niche for a preexisting abnormal hematopoietic stem cell $[4,161-163]$. By chance, the JAK2 mutation is acquired and consequent generation of ROS with clonal expansion and evolution due to genomic instability characterizes the further course of the disease. ROS are also involved in cardiovascular diseases which are major contributors to the comorbidity burden and mortality in MPN patients [11, 15, 96, 98, 99]. Accordingly, the targeting of ROS is an obvious therapeutic option, especially since one of the main goals is to prevent genomic instability, likely facilitated by increased ROS, and thereby ultimately fibrotic and leukemic transformation. In regard to the potent efficacy of NAC in decreasing ROS levels, it is intriguing to consider if NAC treatment might benefit patients with MPNs. The encouraging results from studies in CF, SLE, and COPD warrant such studies.

Furthermore, the antioxidative potential of the widely used agents, IFN, JAK inhibitors, and statins, both as monotherapies and in various combinations, should be investigated. Studies on combinations with IFN, the only agent with the potential to induce "minimal residual disease," as the backbone and "old antioxidative drugs" (statins, NAC) and the novel JAK1/2-inhibitors are urgently needed. Such studies may further enhance the potency of the novel combination therapy with IFN and ruxolitinib, a concept which already has been shown to be highly efficacious in patients with $\mathrm{PV}$ and hyperproliferative MF, implying an improvement in inflammation-mediated comorbidities as well $[28,84,164]$. Such a combinatorial approach using old agents (statins, NAC, and IFN) with anticancer properties (antiproliferative, proapoptotic, antiangiogenic, anti-inflammatory, and antioxidative properties) together with novel JAK1/2 inhibitors may open a new era for patients with MPNs, the outlook not only being "minimal residual disease" and potential cure but also a marked improvement in inflammation-mediated comorbidities. These goals will not only set new standards for treatment of MPNs in the future but may also likely be highly cost-effective when considering the potential of decreasing dosages of very expensive drugs (JAK1/2 inhibitors/ IFN) due to synergism between them and for example, statins, and therefore a reduction in side effects of single agents as well [27, 28, 165-168]. This novel treatment concept, targeting the oxidative stress mechanisms in MPNs, is foreseen to alleviate the heavy disease burden, which encompasses not only an increased risk of severe cardiovascular complications and second cancers but likely also an increased risk of premature 
atherosclerosis (early ageing?) [28, 29, 135]. By eliminating the oxidative stress overload, improving the defective antioxidative stress defence, and improving "Tumor Immune Surveillance" according to the novel treatment concept as outlined above, we are convinced that the future will look bright for our patients and will enlighten new horizons.

\section{Conflict of Interests}

Mads Emil Bjørn has received partial funding for his Ph.D. study from Novartis Oncology. Hans Carl Hasselbalch has received research grants from Novartis Oncology.

\section{Acknowledgments}

Mads Emil Bjørn and Hans Carl Hasselbalch wrote and edited the entire paper.

\section{References}

[1] E. J. Baxter, L. M. Scott, P. J. Campbell et al., "Acquired mutation of the tyrosine kinase JAK2 in human myeloproliferative disorders," The Lancet, vol. 365, no. 9464, pp. 1054-1061, 2005.

[2] C. James, V. Ugo, J.-P. Le Couédic et al., "A unique clonal JAK2 mutation leading to constitutive signalling causes polycythaemia vera," Nature, vol. 434, no. 7037, pp. 1144-1148, 2005.

[3] J. Nangalia, C. E. Massie, E. J. Baxter et al., "Somatic CALR mutations in myeloproliferative neoplasms with nonmutated JAK2," The New England Journal of Medicine, vol. 369, no. 25, pp. 2391-2405, 2013.

[4] M. Cazzola and R. Kralovics, "From Janus kinase 2 to calreticulin: the clinically relevant genomic landscape of myeloproliferative neoplasms," Blood, vol. 123, no. 24, pp. 3714-3719, 2014.

[5] A. Tefferi, J. Thiele, A. M. Vannucchi, and T. Barbui, "An overview on CALR and CSF3R mutations and a proposal for revision of WHO diagnostic criteria for myeloproliferative neoplasms," Leukemia, vol. 28, no. 7, pp. 1407-1413, 2014.

[6] A. Tefferi, "Novel mutations and their functional and clinical relevance in myeloproliferative neoplasms: JAK2, MPL, TET2, ASXL1, CBL, IDH and IKZF1," Leukemia, vol. 24, no. 6, pp. 11281138, 2010.

[7] S. E. Langabeer, H. Andrikovics, J. Asp et al., "Molecular diagnostics of myeloproliferative neoplasms," European Journal of Haematology, 2015.

[8] P. J. Campbell, E. J. Baxter, P. A. Beer et al., "Mutation of JAK2 in the myeloproliferative disorders: timing, clonality studies, cytogenetic associations, and role in leukemic transformation," Blood, vol. 108, no. 10, pp. 3548-3555, 2006.

[9] T. S. Larsen, J. H. Christensen, H. C. Hasselbalch, and N. Pallisgaard, "The JAK2 V617F mutation involves B- and T-lymphocyte lineages in a subgroup of patients with Philadelphia-chromosome negative chronic myeloproliferative disorders," British Journal of Haematology, vol. 136, no. 5, pp. 745-751, 2007.

[10] G. Finazzi, A. Rambaldi, V. Guerini, A. Carobbo, and T. Barbui, "Risk of thrombosis in patients with essential thrombocythemia and polycythemia vera according to JAK2 V617F mutation status," Haematologica, vol. 92, no. 1, pp. 135-136, 2007.

[11] T. Barbui, A. Carobbio, G. Finazzi et al., "Inflammation and thrombosis in essential thrombocythemia and polycythemia vera different role of C-reactive protein and pentraxin 3," Haematologica, vol. 96, no. 2, pp. 315-318, 2011.

[12] T. Barbui, G. Finazzi, and A. Falanga, "Myeloproliferative neoplasms and thrombosis," Blood, vol. 122, no. 13, pp. 21762184, 2013.

[13] C. L. Andersen, M. E. Bjørn, M. F. McMullin et al., "Circulating YKL-40 in patients with essential thrombocythemia and polycythemia vera treated with the novel histone deacetylase inhibitor vorinostat," Leukemia Research, vol. 38, no. 7, pp. 816821,2014

[14] M. E. Bjørn, C. L. Andersen, M. K. Jensen, and H. C. Hasselbalch, "Circulating YKL-40 in myelofibrosis a potential novel biomarker of disease activity and the inflammatory state," European Journal of Haematology, vol. 93, no. 3, pp. 224-228, 2014.

[15] R. Marchioli, G. Finazzi, G. Specchia et al., "Cardiovascular events and intensity of treatment in polycythemia vera," The New England Journal of Medicine, vol. 368, no. 1, pp. 22-33, 2013.

[16] G. Barosi, "An immune dysregulation in MPN," Current Hematologic Malignancy Reports, vol. 9, no. 4, pp. 331-339, 2014.

[17] V. Skov, M. Thomassen, C. H. Riley et al., "Gene expression profiling with principal component analysis depicts the biological continuum from essential thrombocythemia over polycythemia vera to myelofibrosis," Experimental Hematology, vol. 40, no. 9, pp. 771.e19-780.e19, 2012.

[18] A. M. Vannucchi, L. Pieri, and P. Guglielmelli, "JAK2 allele burden in the myeloproliferative neoplasms: effects on phenotype, prognosis and change with treatment," Therapeutic Advances in Hematology, vol. 2, no. 1, pp. 21-32, 2011.

[19] A. Tefferi, P. Guglielmelli, D. R. Larson et al., "Long-term survival and blast transformation in molecularly annotated essential thrombocythemia, polycythemia vera, and myelofibrosis," Blood, vol. 124, no. 16, pp. 2507-2513, 2014.

[20] P. A. Beer, F. Delhommeau, J.-P. LeCouédic et al., “Two routes to leukemic transformation after a JAK2 mutation-positive myeloproliferative neoplasm," Blood, vol. 115, no. 14, pp. 28912900, 2010.

[21] X.-F. Dong, L.-Z. Yue, R. Fu, and Z.-H. Shao, "Polycythemia vera transforming to myelofibrosis and then biphenotype acute leukemia," Clinical Laboratory, vol. 60, no. 3, pp. 495-499, 2014.

[22] S. Y. Kristinsson, O. Landgren, J. Samuelsson, M. Björkholm, and L. R. Goldin, "Autoimmunity and the risk of myeloproliferative neoplasms," Haematologica, vol. 95, no. 7, pp. 1216-1220, 2010.

[23] A. Theocharides, M. Boissinot, F. Girodon et al., "Leukemic blasts in transformed JAK2-V617F-positive myeloproliferative disorders are frequently negative for the JAK2-V617F mutation," Blood, vol. 110, no. 1, pp. 375-379, 2007.

[24] M. N. Kundranda, R. Tibes, and R. A. Mesa, “Transformation of a chronic myeloproliferative neoplasm to acute myelogenous leukemia: does anything work?" Current Hematologic Malignancy Reports, vol. 7, no. 1, pp. 78-86, 2012.

[25] R. A. Mesa, C.-Y. Li, R. P. Ketterling, G. S. Schroeder, R. A. Knudson, and A. Tefferi, "Leukemic transformation in myelofibrosis with myeloid metaplasia: a single-institution experience with 91 cases," Blood, vol. 105, no. 3, pp. 973-977, 2005.

[26] M. L. Heaney and G. Soriano, "Acute myeloid leukemia following a myeloproliferative neoplasm: clinical characteristics, genetic features and effects of therapy," Current Hematologic Malignancy Reports, vol. 8, no. 2, pp. 116-122, 2013. 
[27] H. C. Hasselbalch, "Chronic inflammation as a promotor of mutagenesis in essential thrombocythemia, polycythemia vera and myelofibrosis. A human inflammation model for cancer development?" Leukemia Research, vol. 37, no. 2, pp. 214-220, 2013.

[28] H. C. Hasselbalch, "Perspectives on the impact of JAK-inhibitor therapy upon inflammation-mediated comorbidities in myelofibrosis and related neoplasms," Expert Review of Hematology, vol. 7, no. 2, pp. 203-216, 2014.

[29] H. C. Hasselbalch, "A role of NF-E2 in chronic inflammation and clonal evolution in essential thrombocythemia, polycythemia vera and myelofibrosis?" Leukemia Research, vol. 38, no. 2, pp. 263-266, 2014.

[30] S. Bozinovski, R. Vlahos, D. Anthony et al., "COPD and squamous cell lung cancer: aberrant inflammation and immunity is the common link," British Journal of Pharmacology, 2015.

[31] M. Karin, "Nuclear factor-kappaB in cancer development and progression," Nature, vol. 441, no. 7092, pp. 431-436, 2006.

[32] A. Roslind and J. S. Johansen, Inflammation and Cancer, vol. 511, Humana Press, Totowa, NJ, USA, 2009.

[33] L. M. Coussens and Z. Werb, "Inflammation and cancer," Nature, vol. 420, no. 6917, pp. 860-867, 2002.

[34] E. Elinav, R. Nowarski, C. A. Thaiss, B. Hu, C. Jin, and R. A. Flavell, "Inflammation-induced cancer: crosstalk between tumours, immune cells and microorganisms," Nature Reviews Cancer, vol. 13, no. 11, pp. 759-771, 2013.

[35] G. Trinchieri, "Cancer and inflammation: an old intuition with rapidly evolving new concepts," Annual Review of Immunology, vol. 30, pp. 677-706, 2012.

[36] R. Marchioli, G. Finazzi, R. Landolfi et al., "Vascular and neoplastic risk in a large cohort of patients with polycythemia vera," Journal of Clinical Oncology, vol. 23, no. 10, pp. 2224-2232, 2005.

[37] H. Frederiksen, D. K. Farkas, C. F. Christiansen, H. C. Hasselbalch, and H. T. Sørensen, "Chronic myeloproliferative neoplasms and subsequent cancer risk: a Danish population-based cohort study," Blood, vol. 118, no. 25, pp. 6515-6520, 2011.

[38] H. C. Hasselbalch, "Idiopathic myelofibrosis: a clinical study of 80 patients," American Journal of Hematology, vol. 34, no. 4, pp. 291-300, 1990.

[39] A. Quintás-Cardama, "The role of Janus kinase 2 (JAK2) in myeloproliferative neoplasms: therapeutic implications," Leukemia Research, vol. 37, no. 4, pp. 465-472, 2013.

[40] D. Wolf, J. Rudzki, and G. Gastl, "Current treatment concepts of Philadelphia-negative MPN,” Current Cancer Drug Targets, vol. 11, no. 1, pp. 44-55, 2011.

[41] T. Barbui, G. Barosi, G. Birgegard et al., "Philadelphia-negative classical myeloproliferative neoplasms: critical concepts and management recommendations from European leukemiaNet," Journal of Clinical Oncology, vol. 29, no. 6, pp. 761-770, 2011.

[42] A. Tefferi and W. Vainchenker, "Myeloproliferative neoplasms: molecular pathophysiology, essential clinical understanding, and treatment strategies," Journal of Clinical Oncology, vol. 29, no. 5, pp. 573-582, 2011.

[43] T. S. Larsen, O. W. Bjerrum, N. Pallisgaard, M. T. Andersen, M. B. Møller, and H. C. Hasselbalch, "Sustained major molecular response on interferon alpha- $2 \mathrm{~b}$ in two patients with polycythemia vera," Annals of Hematology, vol. 87, no. 10, pp. 847850, 2008.

[44] T. S. Larsen, M. B. Møller, K. de Stricker et al., "Minimal residual disease and normalization of the bone marrow after long-term treatment with alpha-interferon $2 \mathrm{~b}$ in polycythemia vera. A report on molecular response patterns in seven patients in sustained complete hematological remission," Hematology, vol. 14, no. 6, pp. 331-334, 2009.

[45] J.-J.-J. Kiladjian, B. Cassinat, P. Turlure et al., "High molecular response rate of polycythemia vera patients treated with pegylated interferon $\alpha$-2a," Blood, vol. 108, no. 6, pp. 2037-2040, 2006.

[46] J.-J. Kiladjian, B. Cassinat, S. Chevret et al., "Pegylated interferon-alfa-2a induces complete hematologic and molecular responses with low toxicity in polycythemia vera," Blood, vol. 112, no. 8, pp. 3065-3072, 2008.

[47] A. Quintás-Cardama, H. Kantarjian, T. Manshouri et al., "Pegylated interferon alfa-2a yields high rates of hematologic and molecular response in patients with advanced essential thrombocythemia and polycythemia vera," Journal of Clinical Oncology, vol. 27, no. 32, pp. 5418-5424, 2009.

[48] H. C. Hasselbalch, T. S. Larsen, C. H. Riley, M. K. Jensen, and J.J. Kiladjian, "Interferon-alpha in the treatment of Philadelphianegative chronic myeloproliferative neoplasms. Status and perspectives," Current Drug Targets, vol. 12, no. 3, pp. 392-419, 2011.

[49] J.-J. Kiladjian, R. A. Mesa, and R. Hoffman, "The renaissance of interferon therapy for the treatment of myeloid malignancies," Blood, vol. 117, no. 18, pp. 4706-4715, 2011.

[50] H. C. Hasselbalch, "A new era for IFN-alpha in the treatment of Philadelphia-negative chronic myeloproliferative neoplasms," Expert Review of Hematology, vol. 4, no. 6, pp. 637-655, 2011.

[51] T. Stauffer Larsen, K. F. Iversen, E. Hansen et al., "Long term molecular responses in a cohort of Danish patients with essential thrombocythemia, polycythemia vera and myelofibrosis treated with recombinant interferon alpha," Leukemia Research, vol. 37, no. 9, pp. 1041-1045, 2013.

[52] R. T. Silver, J.-J. Kiladjian, and H. C. Hasselbalch, "Interferon and the treatment of polycythemia vera, essential thrombocythemia and myelofibrosis," Expert Review of Hematology, vol. 6, no. 1, pp. 49-58, 2013.

[53] A. Quintás-Cardama, O. Abdel-Wahab, T. Manshouri et al., "Molecular analysis of patients with polycythemia vera or essential thrombocythemia receiving pegylated interferon $\alpha$ 2a," Blood, vol. 122, no. 6, pp. 893-901, 2013.

[54] B. Cassinat, E. Verger, and J.-J. Kiladjian, "Interferon alfa therapy in CALR-mutated essential thrombocythemia," The New England Journal of Medicine, vol. 371, no. 2, pp. 188-189, 2014.

[55] C. Utke Rank, O. Weis Bjerrum, T. S. Larsen et al., "Minimal residual disease after long-term interferon-alpha2 treatment: a report on hematological, molecular and histomorphological response patterns in 10 patients with essential thrombocythemia and polycythemia vera," Leukemia \& Lymphoma, pp. $1-7,2015$.

[56] C. L. Raison, L. Capuron, and A. H. Miller, "Cytokines sing the blues: inflammation and the pathogenesis of depression," Trends in Immunology, vol. 27, no. 1, pp. 24-31, 2006.

[57] R. Dantzer, J. C. O'Connor, G. G. Freund, R. W. Johnson, and K. W. Kelley, "From inflammation to sickness and depression: when the immune system subjugates the brain," Nature Reviews Neuroscience, vol. 9, no. 1, pp. 46-56, 2008.

[58] P. A. Zunszain, N. Hepgul, and C. M. Pariante, "Inflammation and depression," Current Topics in Behavioral Neurosciences, vol. 14, pp. 135-151, 2013.

[59] E. Antonioli, P. Guglielmelli, L. Pieri et al., "Hydroxyurearelated toxicity in 3,411 patients with Ph'-negative MPN," The 
American Journal of Hematology, vol. 87, no. 5, pp. 552-554, 2012.

[60] M. Björkholm, M. Hultcrantz, and Å. R. Derolf, "Leukemic transformation in myeloproliferative neoplasms: therapyrelated or unrelated?" Bailliere's Best Practice \& Research in Clinical Haematology, vol. 27, no. 2, pp. 141-153, 2014.

[61] J.-J. Kiladjian, S. Chevret, C. Dosquet, C. Chomienne, and J.D. Rain, "Treatment of polycythemia vera with hydroxyurea and pipobroman: final results of a randomized trial initiated in 1980," Journal of Clinical Oncology, vol. 29, no. 29, pp. 3907-3913, 2011.

[62] M.-E. Sirieix, C. Debure, N. Baudot et al., "Leg ulcers and hydroxyurea: forty-one cases," Archives of Dermatology, vol. 135, no. 7, pp. 818-820, 1999.

[63] F. Quattrone, V. Dini, S. Barbanera, N. Zerbinati, and M. Romanelli, "Cutaneous ulcers associated with hydroxyurea therapy," Journal of Tissue Viability, vol. 22, no. 4, pp. 112-121, 2013.

[64] E. Verner, C. Forsyth, and A. Grigg, "Cyclical thrombocytosis, acquired von Willebrand syndrome and aggressive non-melanoma skin cancers are common in patients with Philadelphia-negative myeloproliferative neoplasms treated with hydroxyurea," Leukemia \& Lymphoma, vol. 55, no. 5, pp. 1139-1143, 2014.

[65] A. Heine, S. A. E. Held, S. N. Daecke et al., "The JAK-inhibitor ruxolitinib impairs dendritic cell function in vitro and in vivo," Blood, vol. 122, no. 7, pp. 1192-1202, 2013.

[66] A. Tefferi, "Ruxolitinib targets DCs: for better or worse?" Blood, vol. 122, no. 7, pp. 1096-1097, 2013.

[67] K. Schonberg, J. Rudolph, M. Vonnahme et al., "JAK inhibition impairs NK cell function in myeloproliferative neoplasms," Cancer Research, vol. 75, no. 11, pp. 2187-2199, 2015.

[68] C. Keohane, S. Kordasti, T. Seidl et al., "JAK inhibition induces silencing of $\mathrm{T}$ Helper cytokine secretion and a profound reduction in T regulatory cells," British Journal of Haematology, 2015.

[69] M. Massa, V. Rosti, R. Campanelli, G. Fois, and G. Barosi, "Rapid and long-lasting decrease of T-regulatory cells in patients with myelofibrosis treated with ruxolitinib," Leukemia, vol. 28, no. 2, pp. 449-451, 2014.

[70] B. H. Hahn, "Systemic lupus erythematosus and accelerated atherosclerosis," The New England Journal of Medicine, vol. 349, no. 25, pp. 2379-2380, 2003.

[71] S. P. Yajnanarayana, T. Stübig, I. Cornez et al., "JAK1/2 inhibition impairs T cell function in vitro and in patients with myeloproliferative neoplasms," British Journal of Haematology, vol. 169, no. 6, pp. 824-833, 2015.

[72] Y.-H. Chen, C.-H. Lee, and S.-N. Pei, "Pulmonary tuberculosis reactivation following ruxolitinib treatment in a patient with primary myelofibrosis," Leukemia \& Lymphoma, vol. 56, no. 5, pp. 1528-1529, 2015.

[73] R. K. Hopman, S. J. Lawrence, and S. T. Oh, "Disseminated tuberculosis associated with ruxolitinib," Leukemia, vol. 28, no. 8, pp. 1750-1751, 2014.

[74] F. Palandri, N. Polverelli, L. Catani, and N. Vianelli, "Ruxolitinib-associated tuberculosis: a case of successful ruxolitinib rechallenge," Annals of Hematology, vol. 94, no. 3, pp. 519-520, 2014.

[75] W. Rowan, S. Moule, and D. Milojkovic, "Progressive multifocal leukoencephalopathy associated with ruxolitinib," The New England Journal of Medicine, vol. 369, no. 2, pp. 194-197, 2013.
[76] R. A. Goldberg, E. Reichel, and L. J. Oshry, "Bilateral toxoplasmosis retinitis associated with ruxolitinib," The New England Journal of Medicine, vol. 369, no. 7, pp. 681-683, 2013.

[77] A. Ostojic, R. Vrhovac, and S. Verstovsek, "Ruxolitinib for the treatment of myelofibrosis: its clinical potential," Therapeutics and Clinical Risk Management, vol. 8, pp. 95-103, 2012.

[78] R. A. Mesa, J. Gotlib, V. Gupta et al., "Effect of ruxolitinib therapy on myelofibrosis-related symptoms and other patientreported outcomes in COMFORT-I: a randomized, doubleblind, placebo-controlled trial," Journal of Clinical Oncology, vol. 31, no. 10, pp. 1285-1292, 2013.

[79] S. Verstovsek, R. A. Mesa, J. Gotlib et al., "Efficacy, safety, and survival with ruxolitinib in patients with myelofibrosis: results of a median 3-year follow-up of COMFORT-I," Haematologica, vol. 100, no. 4, pp. 479-488, 2015.

[80] A. Quintás-Cardama, H. Kantarjian, J. Cortes, and S. Verstovsek, "Janus kinase inhibitors for the treatment of myeloproliferative neoplasias and beyond," Nature Reviews Drug Discovery, vol. 10, no. 2, pp. 127-140, 2011.

[81] S. Verstovsek, H. M. Kantarjian, Z. Estrov et al., "Long-term outcomes of 107 patients with myelofibrosis receiving JAK1/JAK2 inhibitor ruxolitinib: survival advantage in comparison to matched historical controls," Blood, vol. 120, no. 6, pp. 12021209, 2012.

[82] F. Passamonti, A. M. Vannucchi, F. Cervantes et al., "Ruxolitinib and survival improvement in patients with myelofibrosis," Leukemia, vol. 3, pp. 739-740, 2015.

[83] M. Kleppe, M. Kwak, P. Koppikar et al., "JAK-STAT pathway activation in malignant and non-malignant cells contributes to MPN pathogenesis and therapeutic response," Cancer Discovery, vol. 5, no. 3, pp. 316-331, 2015.

[84] M. E. Bjørn and H. C. Hasselbalch, "The impact of ruxolitinib treatment on inflammation-mediated comorbidities in myelofibrosis and related neoplasms," Clinical Case Reports, vol. 3, no. 6, pp. 499-503, 2015.

[85] A. Angona, A. Alvarez-Larrán, B. Bellosillo, R. Longarón, C. Fernández-Rodríguez, and C. Besses, "Dynamics of JAK2 $\mathrm{V} 617 \mathrm{~F}$ allele burden of $\mathrm{CD} 34^{+}$haematopoietic progenitor cells in patients treated with ruxolitinib," British Journal of Haematology, 2015.

[86] C. Vener, C. Novembrino, F. B. Catena et al., "Oxidative stress is increased in primary and post-polycythemia vera myelofibrosis," Experimental Hematology, vol. 38, no. 11, pp. 1058-1065, 2010.

[87] C. Marty, C. Lacout, N. Droin et al., "A role for reactive oxygen species in JAK2 V617F myeloproliferative neoplasm progression," Leukemia, vol. 27, no. 11, pp. 2187-2195, 2013.

[88] G. Waris and H. Ahsan, "Reactive oxygen species: role in the development of cancer and various chronic conditions," Journal of Carcinogenesis, vol. 5, article 14, 2006.

[89] C. Gorrini, I. S. Harris, and T. W. Mak, "Modulation of oxidative stress as an anticancer strategy," Nature Reviews Drug Discovery, vol. 12, no. 12, pp. 931-947, 2013.

[90] B. Halliwell, "Oxidative stress and cancer: Have we moved forward?” The Biochemical Journal, vol. 401, no. 1, pp. 1-11, 2007.

[91] Y. Nishinaka, T. Arai, S. Adachi, A. Takaori-Kondo, and K. Yamashita, "Singlet oxygen is essential for neutrophil extracellular trap formation," Biochemical and Biophysical Research Communications, vol. 413, no. 1, pp. 75-79, 2011.

[92] C. Kohchi, H. Inagawa, T. Nishizawa, and G.-I. Soma, "ROS and innate immunity," Anticancer Research, vol. 29, no. 3, pp. 817$822,2009$. 
[93] D. A. Wink, H. B. Hines, R. Y. S. Cheng et al., "Nitric oxide and redox mechanisms in the immune response," Journal of Leukocyte Biology, vol. 89, no. 6, pp. 873-891, 2011.

[94] S. M. Holland, "Chronic granulomatous disease," Clinical Reviews in Allergy \& Immunology, vol. 38, no. 1, pp. 3-10, 2010.

[95] D. B. Kuhns, W. G. Alvord, T. Heller et al., "Residual NADPH oxidase and survival in chronic granulomatous disease douglas," The New England Journal of Medicine, vol. 363, no. 27, pp. 2600-2610, 2010

[96] E. De Marchi, F. Baldassari, A. Bononi, M. R. Wieckowski, and P. Pinton, "Oxidative stress in cardiovascular diseases and obesity: role of p66Shc and protein kinase C," Oxidative Medicine and Cellular Longevity, vol. 2013, Article ID 564961, 11 pages, 2013.

[97] S. Zheng, Z.-M. Zhong, S. Qin et al., "Advanced oxidation protein products induce inflammatory response in fibroblast-like synoviocytes through NADPH oxidase -dependent activation of NF- $\kappa$ B," Cellular Physiology and Biochemistry, vol. 32, no. 4, pp. 972-985, 2013.

[98] U. Singh and I. Jialal, "Oxidative stress and atherosclerosis," Pathophysiology, vol. 13, no. 3, pp. 129-142, 2006.

[99] D. Harrison, K. K. Griendling, U. Landmesser, B. Hornig, and H. Drexler, "Role of oxidative stress in atherosclerosis," The American Journal of Cardiology, vol. 91, no. 3, pp. 7A-11A, 2003.

[100] J. A. Leopold and J. Loscalzo, "Oxidative risk for atherothrombotic cardiovascular disease," Free Radical Biology and Medicine, vol. 47, no. 12, pp. 1673-1706, 2009.

[101] G. Gloire, S. Legrand-Poels, and J. Piette, "NF- $\kappa$ B activation by reactive oxygen species: fifteen years later," Biochemical Pharmacology, vol. 72, no. 11, pp. 1493-1505, 2006.

[102] Y. Ben-Neriah and M. Karin, "Inflammation meets cancer, with NF- $\kappa \mathrm{B}$ as the matchmaker," Nature Immunology, vol. 12 , no. 8 , pp. 715-723, 2011.

[103] M. Karin and F. R. Greten, "NF- $\kappa$ B: linking inflammation and immunity to cancer development and progression," Nature Reviews Immunology, vol. 5, no. 10, pp. 749-759, 2005.

[104] W. S. Alexander, "Suppressors of cytokine signalling (SOCS) in the immune system," Nature Reviews Immunology, vol. 2, no. 6, pp. 410-416, 2002.

[105] W. Sasi, A. K. Sharma, and K. Mokbel, "The role of suppressors of cytokine signalling in human neoplasms," Molecular Biology International, vol. 2014, Article ID 630797, 24 pages, 2014.

[106] D. Capello, C. Deambrogi, D. Rossi et al., "Epigenetic inactivation of suppressors of cytokine signalling in Philadelphianegative chronic myeloproliferative disorders," British Journal of Haematology, vol. 141, no. 4, pp. 504-511, 2008.

[107] N. Fourouclas, J. Li, D. C. Gilby et al., "Methylation of the suppressor of cytokine signaling 3 gene (SOCS3) in myeloproliferative disorders," Haematologica, vol. 93, no. 11, pp. 1635-1644, 2008.

[108] A. V. Ivanov, B. Bartosch, O. A. Smirnova, M. G. Isaguliants, and S. N. Kochetkov, "HCV and oxidative stress in the liver," Viruses, vol. 5, no. 2, pp. 439-469, 2013.

[109] M. H. Khadem Ansari, M.-D. Omrani, and F. Kheradmand, "Oxidative stress response in patients infected by diverse hepatitis C virus genotypes," Hepatitis Monthly, vol. 15, no. 2, Article ID e22069, pp. 1-5, 2015.

[110] W. Lin, W.-L. Tsai, R.-X. Shao et al., "Hepatitis C virus regulates transforming growth factor $\beta 1$ production through the generation of reactive oxygen species in a nuclear factor $\kappa \mathrm{B}$ dependent manner," Gastroenterology, vol. 138, no. 7, pp. 25092518, 2010.
[111] H. Fujinaga, T. Tsutsumi, H. Yotsuyanagi, K. Moriya, and K. Koike, "Hepatocarcinogenesis in hepatitis C: HCV shrewdly exacerbates oxidative stress by modulating both production and scavenging of reactive oxygen species," Oncology, vol. 81, supplement 1, pp. 11-17, 2011.

[112] A. Takaki, "Control of oxidative stress in hepatocellular carcinoma: helpful or harmful?" World Journal of Hepatology, vol. 7, no. 7, p. 968, 2015.

[113] M. Martin and Z. Herceg, "From hepatitis to hepatocellular carcinoma: a proposed model for cross-talk between inflammation and epigenetic mechanisms," Genome Medicine, vol. 4, no. 1, article 8, 2012.

[114] S. Thorsteinsdottir, O. W. Bjerrum, and H. C. Hasselbalch, "Myeloproliferative neoplasms in five multiple sclerosis patients," Leukemia Research Reports, vol. 2, no. 2, pp. 61-63, 2013.

[115] D. Di Bona, M. Cippitelli, C. Fionda et al., "Oxidative stress inhibits IFN- $\alpha$-induced antiviral gene expression by blocking the JAK-STAT pathway," Journal of Hepatology, vol. 45, no. 2, pp. 271-279, 2006.

[116] M. Hurtado-Nedelec, M.-J. Csillag, T. Boussetta et al., "Increased reactive oxygen species production and $\mathrm{p} 47 \mathrm{phox}$ phosphorylation in neutrophils from myeloproliferative disorders patients with JAK2 (V617F) mutation," Haematologica, vol. 98, no. 10, pp. 1517-1524, 2013.

[117] C. Glorieux, M. Zamocky, J. M. Sandoval, J. Verrax, and P. B. Calderon, "Regulation of catalase expression in healthy and Cancer cells," Free Radical Biology and Medicine, 2015.

[118] P. S. Smith, W. Zhao, D. R. Spitz, and M. E. Robbins, "Inhibiting catalase activity sensitizes $36 \mathrm{~B} 10$ rat glioma cells to oxidative stress," Free Radical Biology and Medicine, vol. 42, no. 6, pp. 787797, 2007.

[119] T. S. Hwang, H. K. Choi, and H. S. Han, "Differential expression of manganese superoxide dismutase, copper/zinc superoxide dismutase, and catalase in gastric adenocarcinoma and normal gastric mucosa," European Journal of Surgical Oncology, vol. 33, no. 4, pp. 474-479, 2007.

[120] T. Rainis, I. Maor, A. Lanir, S. Shnizer, and A. Lavy, "Enhanced oxidative stress and leucocyte activation in neoplastic tissues of the colon," Digestive Diseases and Sciences, vol. 52, no. 2, pp. 526530, 2007.

[121] C. S. Sander, F. Hamm, P. Elsner, and J. J. Thiele, "Oxidative stress in malignant melanoma and non-melanoma skin cancer," The British Journal of Dermatology, vol. 148, no. 5, pp. 913-922, 2003.

[122] I. Zelen, P. Djurdjevic, S. Popovic et al., "Antioxidant enzymes activities and plasma levels of oxidative stress markers in Bchronic lymphocytic leukemia patients," Journal of B.U.ON., vol. 15, no. 2, pp. 330-336, 2010.

[123] T. P. Szatrowski and C. F. Nathan, "Production of large amounts of hydrogen peroxide by human tumor cells," Cancer Research, vol. 51, no. 3, pp. 794-798, 1991.

[124] E. C. Vaquero, M. Edderkaoui, S. J. Pandol, I. Gukovsky, and A. S. Gukovskaya, "Reactive oxygen species produced by $\mathrm{NAD}(\mathrm{P}) \mathrm{H}$ oxidase inhibit apoptosis in pancreatic cancer cells," The Journal of Biological Chemistry, vol. 279, no. 33, pp. 3464334654, 2004.

[125] T. Mochizuki, S. Furuta, J. Mitsushita et al., "Inhibition of NADPH oxidase 4 activates apoptosis via the AKT/apoptosis signal-regulating kinase 1 pathway in pancreatic cancer PANC1 cells," Oncogene, vol. 25, no. 26, pp. 3699-3707, 2006.

[126] N. Li, K. Ragheb, G. Lawler et al., "Mitochondrial complex I inhibitor rotenone induces apoptosis through enhancing 
mitochondrial reactive oxygen species production," Journal of Biological Chemistry, vol. 278, no. 10, pp. 8516-8525, 2003.

[127] S. Yalcin, D. Marinkovic, S. K. Mungamuri et al., "ROSmediated amplification of AKT/mTOR signalling pathway leads to myeloproliferative syndrome in Foxo $3^{-/-}$mice," The EMBO Journal, vol. 29, no. 24, pp. 4118-4131, 2010.

[128] D. Xu, H. Zheng, W.-M. Yu, and C.-K. Qu, "Activating mutations in protein tyrosine phosphatase Ptpn11 (Shp2) enhance reactive oxygen species production that contributes to myeloproliferative disorder," PLOS ONE, vol. 8, no. 5, Article ID e63152, 2013.

[129] P. S. Goerttler, C. Kreutz, J. Donauer et al., "Gene expression profiling in polycythaemia vera: overexpression of transcription factor NF-E2," British Journal of Haematology, vol. 129, no. 1, pp. 138-150, 2005.

[130] M. Mutschler, A. S. Magin, M. Buerge et al., "NF-E2 overexpression delays erythroid maturation and increases erythrocyte production," British Journal of Haematology, vol. 146, no. 2, pp. 203-217, 2009.

[131] K. B. Kaufmann, A. Gründer, T. Hadlich et al., "A novel murine model of myeloproliferative disorders generated by overexpression of the transcription factor NF-E2," Journal of Experimental Medicine, vol. 209, no. 1, pp. 35-50, 2012.

[132] K. Aumann, A.-V. Frey, A. M. May et al., "Subcellular mislocalization of the transcription factor NF-E2 in erythroid cells discriminates prefibrotic primary myelofibrosis from essential thrombocythemia," Blood, vol. 122, no. 1, pp. 93-99, 2013.

[133] J. Wehrle, T. S. Seeger, S. Schwemmers, D. Pfeifer, A. Bulashevska, and H. L. Pahl, "Transcription factor nuclear factor erythroid-2 mediates expression of the cytokine interleukin 8 , a known predictor of inferior outcome in patients with myeloproliferative Neoplasms," Haematologica, vol. 98, no. 7, pp.10731080, 2013.

[134] R. Bogeska and H. L. Pahl, "Elevated nuclear factor erythroid2 levels promote epo-independent erythroid maturation and recapitulate the hematopoietic stem cell and common myeloid progenitor expansion observed in polycythemia vera patients," Stem Cells Translational Medicine, vol. 2, no. 2, pp. 112-117, 2013.

[135] H. C. Hasselbalch, M. Thomassen, C. H. Riley et al., "Whole blood transcriptional profiling reveals deregulation of oxidative and antioxidative defence genes in myelofibrosis and related neoplasms. Potential implications of downregulation of Nrf2 for genomic instability and disease progression," PLoS ONE, vol. 9, no. 11, Article ID el12786, 2014.

[136] M. Nakatake, B. Monte-Mor, N. Debili et al., "JAK2 $2^{V 617 F}$ negatively regulates p53 stabilization by enhancing MDM2 via La expression in myeloproliferative neoplasms," Oncogene, vol. 31, no. 10, pp. 1323-1333, 2012.

[137] C. Cybulski, B. Górski, T. Huzarski et al., "CHEK2 is a multiorgan cancer susceptibility gene," The American Journal of Human Genetics, vol. 75, no. 6, pp. 1131-1135, 2004.

[138] M. Simon, M. Ludwig, R. Fimmers et al., "Variant of the CHEK2 gene as a prognostic marker in glioblastoma multiforme," Neurosurgery, vol. 59, no. 5, pp. 1078-1085, 2006.

[139] X. Wu, X. Dong, W. Liu, and J. Chen, "Characterization of CHEK2 mutations in prostate cancer," Human Mutation, vol. 27, no. 8, pp. 742-747, 2006.

[140] J. Suchy, C. Cybulski, D. Wokołorczyk et al., "CHEK2 mutations and HNPCC-related colorectal cancer," International Journal of Cancer, vol. 126, no. 12, pp. 3005-3009, 2010.

[141] E. Złowocka, C. Cybulski, B. Górski et al., "Germline mutations in the CHEK2 kinase gene are associated with an increased risk of bladder cancer," International Journal of Cancer, vol. 122, no. 3, pp. 583-586, 2008.

[142] H. Janiszewska, A. Bak, M. Pilarska et al., "A risk of essential thrombocythemia in carriers of constitutional CHEK2 gene mutations," Haematologica, vol. 97, no. 3, pp. 366-370, 2012.

[143] H. Janiszewska, A. Bąk, M. Hartwig et al., "The germline mutations of the CHEK2 gene are associated with an increased risk of polycythaemia vera," British Journal of Haematology, 2015.

[144] Y. Zhang, X. Liu, C. McHale et al., "Bone marrow injury induced via oxidative stress in mice by inhalation exposure to formaldehyde," PLoS ONE, vol. 8, no. 9, Article ID e74974, 2013.

[145] T. Yahata, T. Takanashi, Y. Muguruma et al., "Accumulation of oxidative DNA damage restricts the self-renewal capacity of human hematopoietic stem cells," Blood, vol. 118, no. 11, pp. 2941-2950, 2011.

[146] A. Mullally, C. Bruedigam, L. Poveromo et al., "Depletion of Jak2V617F myeloproliferative neoplasm-propagating stem cells by interferon- $\alpha$ in a murine model of polycythemia vera," Blood, vol. 121, no. 18, pp. 3692-3702, 2013.

[147] S. Hasan, C. Lacout, C. Marty et al., "JAK2V617F expression in mice amplifies early hematopoietic cells and gives them a competitive advantage that is hampered by IFN $\alpha$, Blood, vol. 122, no. 8, pp. 1464-1477, 2013.

[148] C. H. Riley, M. Hansen, M. K. Brimnes et al., "Expansion of circulating CD56 $6^{\text {bright }}$ natural killer cells in patients with JAK2positive chronic myeloproliferative neoplasms during treatment with interferon- $\alpha$, European Journal of Haematology, vol. 94, no. 3, pp. 227-234, 2015.

[149] V. Skov, C. H. Riley, M. Thomassen et al., "Whole blood transcriptional profiling reveals significant down-regulation of human leukocyte antigen class I and II genes in essential thrombocythemia, polycythemia vera and myelofibrosis," Leukemia \& Lymphoma, vol. 54, no. 10, pp. 2269-2273, 2013.

[150] A. Karalija, L. N. Novikova, P. J. Kingham, M. Wiberg, and L. N. Novikov, "Neuroprotective effects of N-acetyl-cysteine and acetyl-L-carnitine after spinal cord injury in adult rats," PLoS ONE, vol. 7, no. 7, Article ID e41086, 2012.

[151] A. Karalija, L. N. Novikova, P. J. Kingham, M. Wiberg, and L. N. Novikov, "The effects of N-acetyl-cysteine and acetyl-1carnitine on neural survival, neuroinflammation and regeneration following spinal cord injury," Neuroscience, vol. 269, pp. 143-151, 2014.

[152] F. Shen, C. V. Coulter, G. K. Isbister, and S. B. Duffull, "A dosing regimen for immediate $\mathrm{N}$-acetylcysteine treatment for acute paracetamol overdose," Clinical Toxicology, vol. 49, no. 7, pp. 643-647, 2011.

[153] L. E. Schmidt, "Identification of patients at risk of anaphylactoid reactions to $\mathrm{N}$-acetylcysteine in the treatment of paracetamol overdose," Clinical Toxicology, vol. 51, no. 6, pp. 467-472, 2013.

[154] Y. Shen, W. Cai, S. Lei, and Z. Zhang, "Effect of high/low dose $\mathrm{N}$-acetylcysteine on chronic obstructive pulmonary disease: a systematic review and meta-analysis," Journal of Chronic Obstructive Pulmonary Disease, vol. 11, no. 3, pp. 351-358, 2014.

[155] P. Santus, A. Corsico, P. Solidoro, F. Braido, F. Di Marco, and N. Scichilone, "Oxidative stress and respiratory system: pharmacological and clinical reappraisal of N-acetylcysteine," Journal of Chronic Obstructive Pulmonary Disease, vol. 11, no. 6, pp. 705-717, 2014.

[156] C. Conrad, J. Lymp, V. Thompson et al., "Long-term treatment with oral $\mathrm{N}$-acetylcysteine: affects lung function but not sputum inflammation in cystic fibrosis subjects. A phase II randomized 
placebo-controlled trial," Journal of Cystic Fibrosis, vol. 14, no. 2, pp. 219-227, 2015.

[157] Z.-W. Lai, R. Hanczko, E. Bonilla et al., "N-acetylcysteine reduces disease activity by blocking mammalian target of rapamycin in $\mathrm{T}$ cells from systemic lupus erythematosus patients: a randomized, double-blind, placebo-controlled trial," Arthritis and Rheumatism, vol. 64, no. 9, pp. 2937-2946, 2012.

[158] V. Skov, T. S. Larsen, M. Thomassen et al., "Whole-blood transcriptional profiling of interferon-inducible genes identifies highly upregulated IFI27 in primary myelofibrosis," European Journal of Haematology, vol. 87, no. 1, pp. 54-60, 2011.

[159] V. Skov, T. S. Larsen, M. Thomassen et al., "Molecular profiling of peripheral blood cells from patients with polycythemia vera and related neoplasms: identification of deregulated genes of significance for inflammation and immune surveillance," Leukemia Research, vol. 36, no. 11, pp. 1387-1392, 2012.

[160] C. H. Riley, M. K. Jensen, M. K. Brimnes et al., "Increase in circulating $\mathrm{CD}^{+} \mathrm{CD} 25^{+} \mathrm{Foxp}^{+} \mathrm{T}$ cells in patients with Philadelphia-negative chronic myeloproliferative neoplasms during treatment with IFN- $\alpha$," Blood, vol. 118, no. 8, pp. 21702173, 2011.

[161] M.-C. Le Bousse-Kerdilès, "Primary myelofibrosis and the "bad seeds in bad soil' concept," Fibrogenesis \& Tissue Repair, vol. 5, supplement 1, article S20, 2012.

[162] J.-J. Lataillade, O. Pierre-Louis, H. C. Hasselbalch et al., "Does primary myelofibrosis involve a defective stem cell niche? From concept to evidence," Blood, vol. 112, no. 8, pp. 3026-3035, 2008.

[163] P. Lundberg, A. Karow, R. Nienhold et al., "Clonal evolution and clinical correlates of somatic mutations in myeloproliferative neoplasms," Blood, vol. 123, no. 14, pp. 2220-2228, 2014.

[164] M. Bjørn, K. de Stricker, L. Kjær, K. Ellemann, and H. C. Hasselbalch, "Combination therapy with interferon and JAK12 inhibitor is feasible: proof of concept with rapid reduction in JAK2V617F-allele burden in polycythemia vera," Leukemia Research Reports, vol. 3, no. 2, pp. 73-75, 2014.

[165] H. C. Hasselbalch, "The role of cytokines in the initiation and progression of myelofibrosis," Cytokine \& Growth Factor Reviews, vol. 24, no. 2, pp. 133-145, 2013.

[166] H. C. Hasselbalch and C. H. Riley, "Statins in the treatment of polycythaemia vera and allied disorders: an antithrombotic and cytoreductive potential?" Leukemia Research, vol. 30, no. 10, pp. 1217-1225, 2006.

[167] H. C. Hasselbalch, "Perspectives on chronic inflammation in essential thrombocythemia, polycythemia vera, and myelofibrosis: Is chronic inflammation a trigger and driver of clonal evolution and development of accelerated atherosclerosis and second cancer?" Blood, vol. 119, no. 14, pp. 3219-3225, 2012.

[168] L. N. Griner, K. L. Mcgraw, J. O. Johnson, A. F. List, and G. W. Reuther, "JAK2-V617F-mediated signalling is dependent on lipid rafts and statins inhibit JAK2-V617F-dependent cell growth," British Journal of Haematology, vol. 160, no. 2, pp. 177187, 2013. 


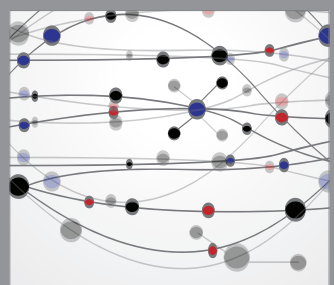

The Scientific World Journal
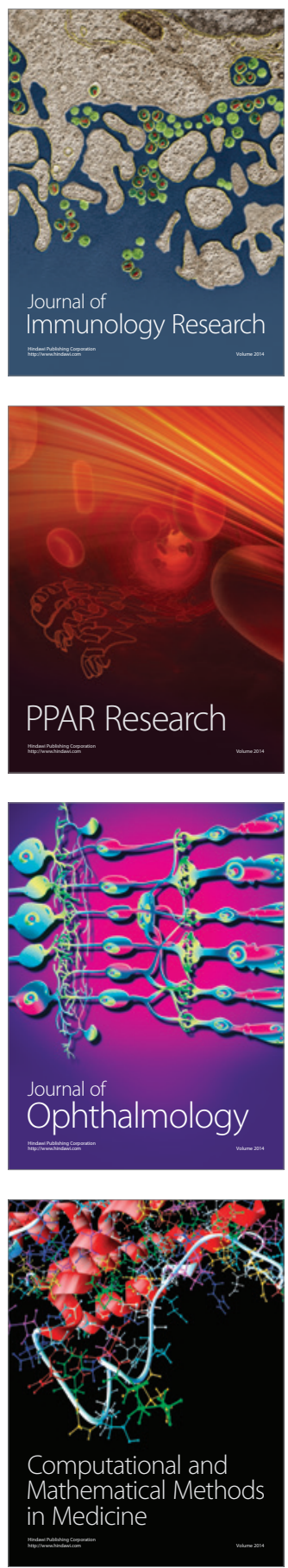

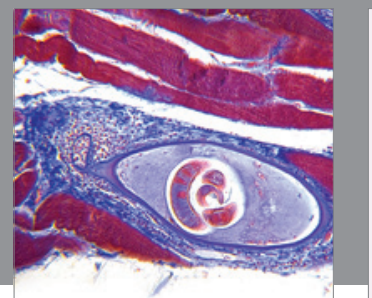

Gastroenterology

Research and Practice
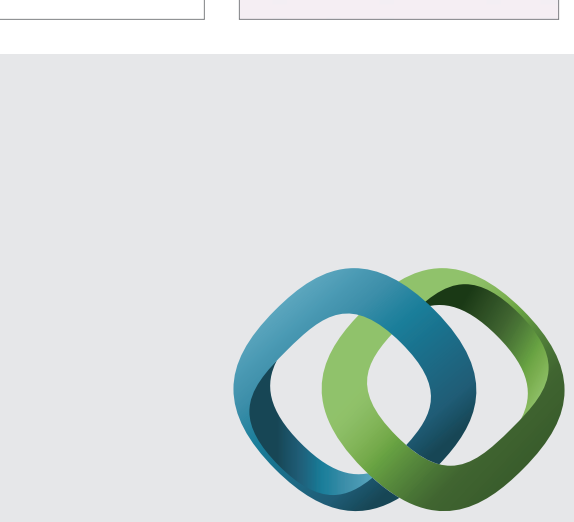

\section{Hindawi}

Submit your manuscripts at

http://www.hindawi.com
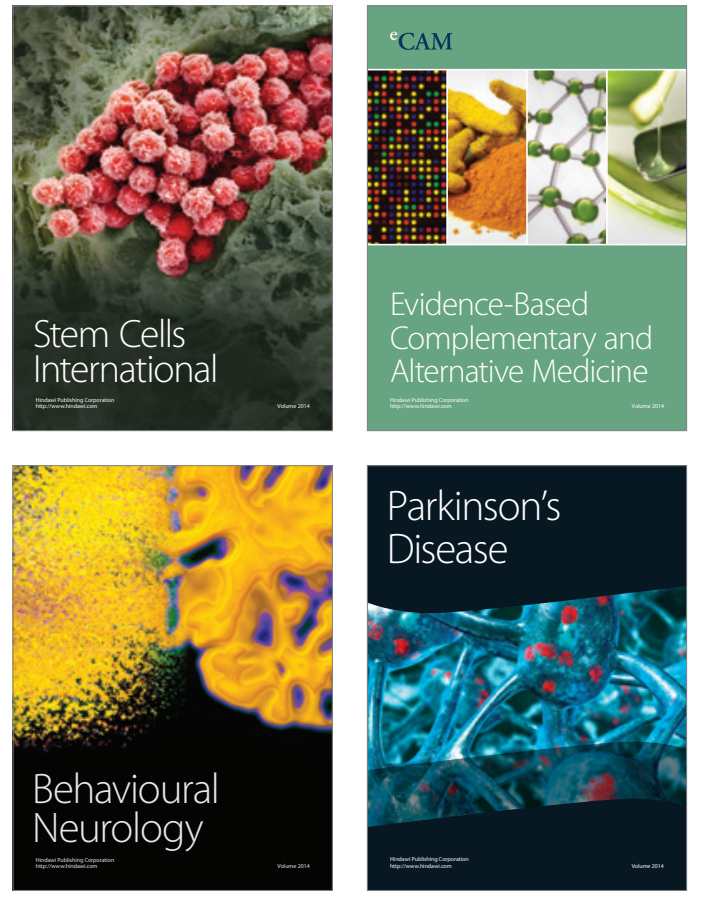
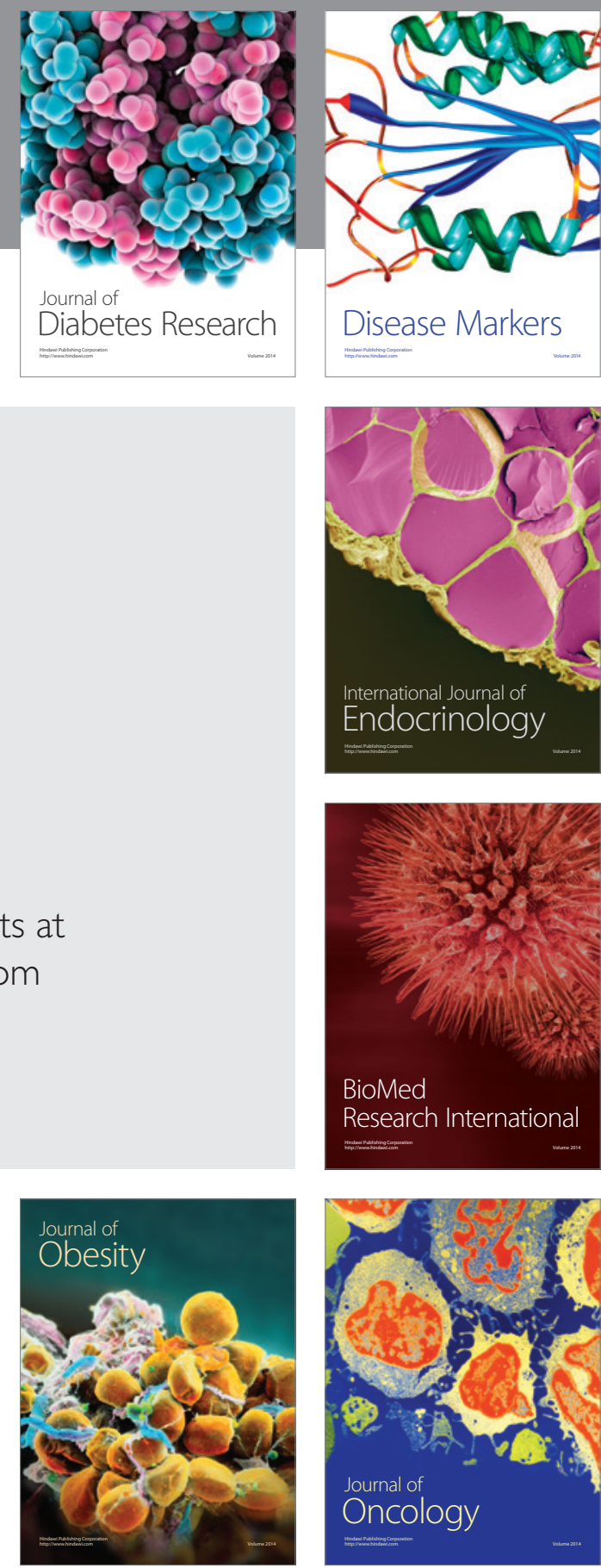

Disease Markers
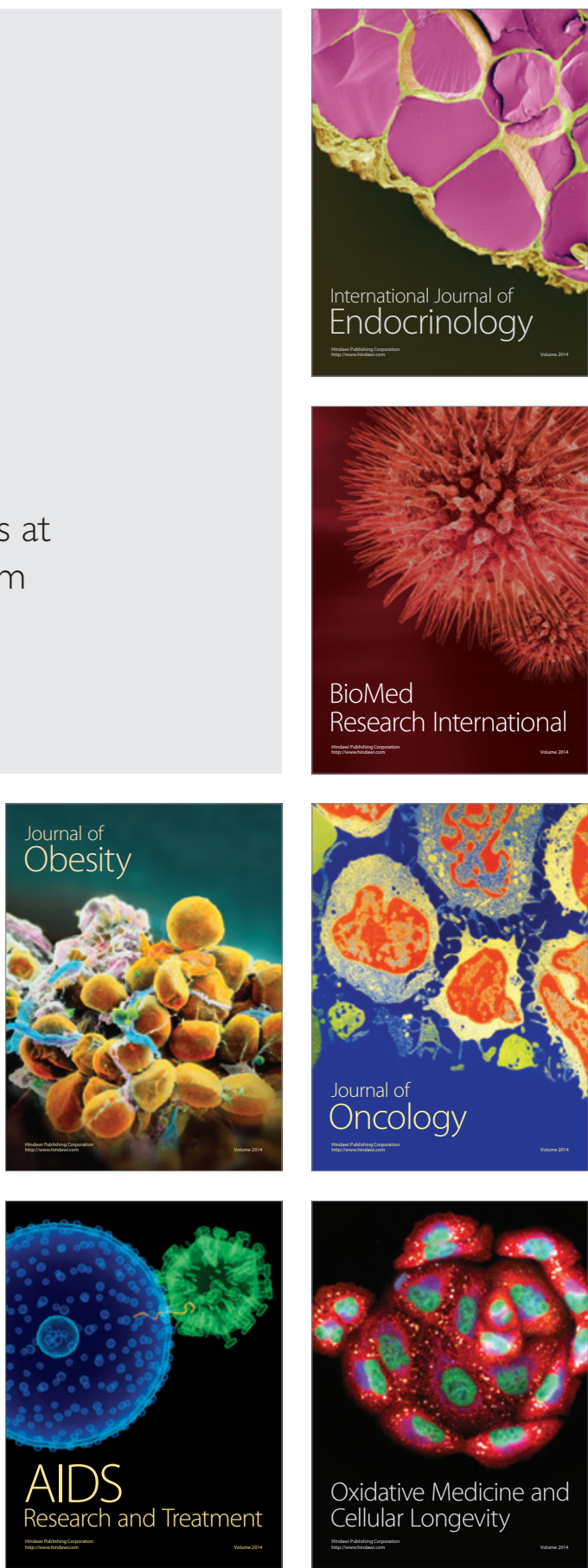